culty: occasionally cramped passages would require investigation. Do my written translations show ignorance of the language? My Greek I could easily have prepared; but before leaving England, I was expressly told by the secretary of the College that I should only be required to translate ver'bally some Latin medical author; and what other interpretation could I pat upon the following:-

"If he declines this, he is, at any rate, expected to construe into English a portion of the works of Celsus, or Sydenham, or some other Latin medical author."

This was sent to the London Medical Directory by the College, although when I quoted it, Dr. Paris said in an angry tone, "We have nothing, Sir, to do with the Directory." I had told Dr. Alderson before the written examination, that I did not suppose that I should have been called upon to answer questions in Latin, or even to give a written translation of the Latin. Dr. Todd knew (see his letter) that I was admitted under the by-law affecting those beyond forty years of age; but when questions were put to me in Latin, his friendship did not allow him to interpose, although, when I asked the president a question, respecting the manimity of the examiners, he rudely interfered.

8. I call upon Dr. Todd to state publicly that he had forgotten the case in question?

9. I said I knew not by whom these four questions were put; the coincidence, I thought, was a curious one.*

10. The gentleman in question refused to allow the practical errors to be put down in writing; but Dr. Todd, I am sure, will do this.

11. The accidental burning of the papers must be explained. Who burnt them? and by whose orders were they burnt? And perhaps Dr. Todd will state whether a ballot took place? whether the lunatic asylum was talked of before my final condennation? and whether he had reason to believe that some of the examiners intended to reject me from the beginning? Likewise, what the nature of the communication was that Mr. Sedgwick was ordered to read to me?

I think, Sir, you and your readers will agree with me, that although Dr. Todd has hitherto been advised by all his aristocratic fricnds not to notice my pamphlet, he cannot now, as a gentleman and a man of honour, refrain from giving a full and explicit reply; and that I am acting the part of a firiend in affording him an opportunity of doing so.

I am, Sir, your obedient servant,

Norfolk street, Strand, March, 1849.

Edwards Crisp.

\section{NON-DETECTION OF NITRIC ACID IN THE URINE.}

To the Editor of The Lancet.

Srn,-A letter appeared in your journal of last Saturday, which refers to a paper by me, read before the MedicoChirurgical Society, on the Employment of the Nitrate of Potass in Acute Rheumatism; and the writer inquires by what means nitrate of potass was detected in the urine; stating, that he had endeavoured to ascertain the presence of nitric acid by the most delicate tests, and had been unsuccessful in discovering the smallest trace. I employ the following method :-A portion of the urine to be examined for the nitrate is evaporated in a water bath, to the consistence of syrup. It is then well washed with a mixture of alcohol (specific gravity 840) and ether. The ethereal spirit is decanted off, and the residue dissolved in a small quantity of distilled water, filtered, and if the amount of distiiled water renders it necessary, concentrated by evaporation. The solution is then introduced into a tube, into which a small and pure crystal of the proto-sulphate of iron has been dropped; concentrated snlphuric acid is then added by means of a pipetto, and the whole heated in a spirit lamp. If nitrate of potass be present, the solution requires an orange brown tint from the conversion of the proto-salt of iron into a persalt. This should be proved by the reaction of a few drops of a solution

* As the late Dr. Clendinning's name has been alluded to, I may mention a circumstance, which should teach all Irsurance Offices that it is to their interest to pay their medical referees. A young gentleman, of a consump tive family, whom $I$ had attended for some years, was anxious to insure hi life. I refused to answer the questions, as no fee was sent. Dr. Clendinning, who was the medical referee, passed him; but the gentleman died of pneumonia and tubcrcle a short time afterwards. The directors complained that Dr. Clendinning had not detected the tubercular deposit. Dr. Clen dinning, who was a stranger to me, wrote for my account of the inspection. I sent it; and stated, at the same time, that if the most experienced stethoscopist had seen the patient when Dr. Clendinning did, lie would probably not have detected the presence of tubercle. This part of my letter was read to the diret tors. I had the advantage of knowing this gentleman' constitution; and on this account, should not have considered his life eligible for insurance. $-\mathrm{E}$. C. of the ferricyanide of potassium $\left(K_{2}\right.$ Cfy $)$. By this process, very moderate quantities of the nitrate may be detected in the urine; and with some trifling modifications of this process, the salt has been detected in the blood of those who have been taking nitrate of potass in acute rheumatism. In the examination of the urine for the presence of agents that have been employed internally, the rapidity with which these salts are carried off by the kidneys must not be overlooked, and al the urine excreted during the administration, and for some hours after the discontinuance of the remedy, should be carefully collected for examination.

I am, Sir, your obedient servant,

Chester-street, Grosvenor-place, March, 1819. W. H. BASHAMr.

\section{THE FIVE HUNDRED POUNDS MEDICAL REFORM FUND.}

To the Elitor of The Lancet.

Sin,-I am desirous that my name should be added to the list of subscribers to the "Five IIundred Pounds Medical Reform Fund," and I hereby promise to pay a sovereign towards it when called upon to do so.

I am, Sir, your obedient servant

Colne, March, 1849.

To the Editor of The Lancet.

Srr,-I beg to say I shall be happy to contribute my 10s. to the "Five Hundred Pounds Medical Reform Fund" whenever called upon, should the promises amount to that sum.

I do so with a firm reliance, however, that the committee, when formed, will resist to the uttermost the contemplated robbery on surgeons and general practitioners, by depriving them of their M.D. degrees, or any other proviously acquired honours or qualifications, duly recognised and legally obtained. I am, Sir, your obedient servant

Kidderminster, March, $18 \pm 9$. WILLIAM RODEN, M.D.
Mayor of the Borough.

Mr. Lew Is's compliments to the Editor of THe LANCET, and begs to inform him that he is prepared to subscribe the sum of 10s. to the "Five Mundred Pounc's Medical Reform Fund." New Kent-road, March, Is49.

\section{To the Editor of 'THE LANCET.}

Srr,--I sha!l feel obliged if you will add my name for the sum of one guinea to the " Five Hundred Pounds Medical Reform Fund," to oppose the medical bill of the National Institute, \&c.

I may now, in reply to your "M.D." correspondent of last week, inform him that I never condescend to notice anonymous scribblers, who have not the good sense or courage to sign their names, or I could readily show him my assertion as to the cost of the M.D. degree was perfectly correct.

I am, Sir, your obedient servant,
Cheltenham, March, 1819.

\section{To the Editor of The LANCET.}

SIR,-I shall feel much obliged by your adding my name to the contributors of the "Medical Reform Fund" for the sum of $10 s .$, which I will forward when called upon. Sir, yours respectfully,

Flegg Burgh, Nol folk, March, 1849 . JomN T. WALLER, M.R.C.S.L.

\section{To the Editor of THE LANCET.}

Sir,-I beg you will add my name, for half-a-guinea, to the list of subscribers to the medical protection fund. Hoping sincerely that this grand object may be affected, I ain, Sir, yours obediently,
Judd-street, March, 1849.
W. Hong Popham.

To the Elitor of THE LANCET.

Sir,-Please to put my name, and that of Mr. Paul Jackson, 18, 'Thayer-street, Manchester-square, as subscribers to the Five IIundred Pounds Fund.- Your obedient servant, Wimpole-street, March, 1819.

EDwin Moss.

\section{THE NECESSITY FOR MEDICAL REFORM.}

To the Editor of TuE Larcer.

Srr,-As a subscriber to your talented and widely circulating journal, I cannot but admire your powerful advocacy for medical reform; your often repeated and time-telling onslaughts on quacks and quackery, in and out of the profession. 